\title{
Thermal mending in novel epoxy/cyclic olefin copolymer blends
}

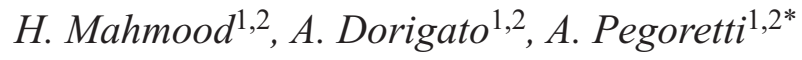 \\ ${ }^{1}$ Department of Industrial Engineering, University of Trento, Via Sommarive, 938123 Trento, Italy \\ ${ }^{2}$ National Interuniversity Consortium of Materials Science and Technology (INSTM), Via Giusti, 950121 Florence, Italy
}

Received 6 September 2019; accepted in revised form 8 November 2019

\begin{abstract}
In this paper, the thermal mending potential of a cyclic olefin copolymer (COC) in a thermosetting matrix was evaluated for the first time. Epoxy/COC blends were prepared by mechanically mixing a COC powder (particle size lower than $300 \mu \mathrm{m})$ at different concentrations $(10,20,30$ and $40 \mathrm{wt} \%)$ in an epoxy resin in the uncured (liquid) state. The presence of a homogenous dispersion of COC particles within the epoxy matrix after curing was confirmed by optical microscopy analysis on polished specimens. Thermogravimetric tests evidenced a positive contribution of the thermoplastic COC phase on the thermal degradation resistance of the blends. The fracture toughness of the blends (both under quasi-static and Charpy impact conditions) increased with the addition of COC. Healing tests were performed on broken samples after healing under a compressive stress of $15 \mathrm{MPa}$ at $190^{\circ} \mathrm{C}$ for 1 hour. A significant increase of the healing efficiency with the COC content was detected, and healing efficiency values very near to $100 \%$ were obtained for a COC content of $40 \mathrm{wt} \%$.
\end{abstract}

Keywords: mechanical properties, healing, blends, epoxy, fracture toughness

\section{Introduction}

In the $21^{\text {st }}$ century, technological applications of fiber reinforced polymer composites (FRPCs) have grown at an exponential rate. For instance, the new generation of commercial aircrafts have successfully used FRPCs as a primary material, notably Airbus A350 XWB (53 wt\%) and Boeing 787 Dreamliner $(50 \mathrm{wt} \%)$ [1]. Also, in the automotive field, body panels, interiors, chassis, hoods and other parts of modern cars are constituted by FRPCs. The primary reason for this choice is the high strength-to-weight ratio offered by composite structures, which is crucial for the improvements of the fuel efficiency of the vehicles. Moreover, also sports equipment and wind turbine blades enjoy the improved performance of such lightweight structures. As a result of their intrinsic heterogeneity, FPRCs are often characterized by complex failure mechanisms. During the first stages of the damage evolution, cracks and defects propagation is mainly located in the matrix. These cracks are very difficult to be detected with the common diagnostic techniques [2]. The identification of the damage within composite structures and implementation of possible repairing mechanisms is therefore very important [3-5], as these aspects often limit the use of FRPCs in applications where safety is a key requirement [6]. Replication of healing mechanisms commonly found in biological systems has been thus investigated in the last decade, with the aim to repair the damage in polymer-based structures during the initial crack propagation stage. Therefore, a growing interest arose in the development of selfhealing composites that could heal themselves several times, extending thus their lifetime.

Self-healing systems are normally divided into two main categories i.e. extrinsic and intrinsic systems. 
The extrinsic systems are constituted by a healing agent incorporated in the structure in different forms (i.e. capsules or vascular networks). When crack propagates in the structure, the healing agent is released and repairs the matrix by filling the crack front [7-10]. Among the advantages of such systems, one can list the autonomous repairability with healing efficiency approaching $100 \%$, especially when the degree of damage is below a critical threshold. The major drawback of these materials is that the healing process can be activated only one time, as the thermosetting nature of these healing systems does not permit multiple healing events. Moreover, the complexity of creating microspheres or vascular networks makes the fabrication of such composites on industrial scale quite challenging, and also the thermal and environmental stability of microcapsules itself represents a strong limitation. On the other hand, intrinsic self-healing systems are based on reversible chemical or physical bonds which are driven by the molecular mobility through the application of an external stimuli $[11,12]$. In this case, healing is possible without the inclusion of monomers and/or catalysts, but external heat and/or pressure is required to trigger the mending process. One type of intrinsic system involves the thermal activation of a crosslinked polymer through Diels-Alder (DA) and retro-DA (rDA) reactions [13]. Such $\mathrm{DA} / \mathrm{rDA}$ reactions allow repeatable healing events in different polymer systems (e.g. epoxy (EP), polyethylene $(\mathrm{PE})$ and polyamide (PA)), through the application of healing treatments from 100 to $150^{\circ} \mathrm{C}$, for a duration ranging from $10 \mathrm{~min}$ up to $2 \mathrm{~h}$ [14-22].

Another intrinsic self-healing mechanism involves the use of a thermoplastic polymer as solid-state healing agent in a thermosetting matrix. Such thermoplastic materials can be molten/softened upon the combined action of heat and pressure, hence repairing, after interdiffusion and solidification, the cracks within the thermosetting matrix in which they are dispersed. In order to effectively heal the cracks, a thermoplastic healing agent should possess three key features: (i) low melting/softening point and viscosity to achieve flowability of the healing agent in the cracks, (ii) functional groups being reactive to the hosting matrix, and (iii) good adhesive properties to obtain a strong hydrogen bonding with the matrix during crack mending [23]. Up to now, various thermoplastic matrix have been investigated as possible healing agents for thermosettings, such as
(poly(bisphenol-A-co-epichlorohydrin) [24-26], poly (E-caprolactone) (PCL) [27-29], poly(vinylacetate) (PVAc) [30], poly(ethylene-co-methyl acrylate) (EMA) [31] and poly(ethylene-co-methacrylic acid) (EMAA) [32, 33]. For instance, Hayes et al. [24, 25] considered a linear copolymer (polybisphenol-A-coepichlorohydrin) thermoplastic healing matrix in an epoxy resin, reporting an healing efficiency under impact conditions of $65 \%$ with an healing agent concentration of $7.5 \mathrm{wt} \%$. Meure et al. [34] reported for the first time the use of polyethylene-co-methacrylic acid as healing agent in an epoxy resin. The authors obtained a degree of recovery of the critical stress intensity factor $\left(K_{\text {Ic }}\right)$ of the $85 \%$. Pingkarawat et al. [35] studied the healing mechanism of epoxy resins in which reactive a thermoplastic matrix, like polyethylene-co-methacrylic acid (EMAA) and polyethylene-co-glycidyl methacrylate (PEGMA), and nonreactive thermoplastics, like ethylene vinyl acetate (EVA) and acrylonitrile butadiene styrene (ABS), were dispersed. The authors reported a partial mending of the fractured epoxy using these thermoplastic systems, evidencing also the different mechanisms that activated the healing process. In other papers low melting point thermoplastic polymers, such as PCL, were blended with an epoxy matrix, obtaining thermal mending with efficiencies exceeding 100\% [36-39]. Interestingly, cyclic olefin copolymers (COCs) have not been yet considered as thermoplastic healing additive in an epoxy matrix. COC is an amorphous polymer that can be synthesized through the copolymerization of norbornene and ethylene, and possesses outstanding mechanical and optical properties, elevated stiffness, high chemical resistance, good low moisture absorption, moisture barrier properties and low density [40-42]. Because of their peculiar properties, COCs are generally used for the production of transparent parts (i.e. lenses, and sensors), pharmaceutical packaging, and medical devices. Changing the norbornene content, various COC grades with different glass-transition temperatures $\left(T_{\mathrm{g}}\right)$ can be produced [43-45]. One of the key features of the present work is that the selected COC grade possesses physical and mechanical properties comparable to that of the epoxy resin, i.e. $T_{\mathrm{g}} \approx 80^{\circ} \mathrm{C}$, elastic modulus of $2250 \mathrm{MPa}$, tensile strength of $45 \mathrm{MPa}$ and limited tensile strain at break (about 5\%). In the past works, healing agents (i.e. PCL, EMAA, polybisphenol-A-co-epichlorohydrin etc.) were generally selected on the basis of their low viscosity in 
the molten state and their limited melting point, without considering their mechanical features. In the authors opinion, it could be important to take also this aspect into account, thus evaluating the healing effectiveness of an amorphous thermoplastic matrix coupled with an epoxy resin having similar properties. On the basis of these considerations, the aim of this work is to evaluate for the first time the thermal mending potential of an amorphous COC matrix within an epoxy system, that could be potentially used as a matrix for structural composites. At this aim, different amounts of COC powder were dispersed in the liquid resin. After the curing process, a complete microstructural and thermomechanical characterization of the resulting blends was performed. Moreover, the fracture behavior of both virgin and healed epoxy/ COC blends was investigated under quasi-static and impact conditions, in order to evaluate the thermal mending capability of COC.

\section{Materials and methods}

\subsection{Materials}

A bi-component epoxy system, constituted by an epoxy base (EC157) and an amine hardener (W 342), kindly provided by Elantas Europe Srl (Collecchio, Italy), was used as a thermosetting matrix. COC granules of TOPAS ${ }^{\circledR} 8007$, supplied by Ticona (Kelsterbach, Germany), consisting of $65 \mathrm{wt} \%$ ethylene and $35 \mathrm{wt} \%$ norbornene (melt flow index at $190^{\circ} \mathrm{C}$ and $2.16 \mathrm{~kg}=1.7 \mathrm{~g} / 10 \mathrm{~min}$, density $=1.02 \mathrm{~g} / \mathrm{cm}^{3}$, $T_{\mathrm{g}}=78^{\circ} \mathrm{C}$ ), were adopted as amorphous healing agent. In Figure 1 the chemical structure of this polymer is reported. All the materials in this work were used as received, without any further treatment.

\subsection{Preparation of the samples}

COC granules were cryogenically milled by using an IKA Labortechnik M20 (IKA ${ }^{\circledR}$-Werke GmbH, Staufen, Germany) electric grinding machine, and then sieved to obtain a powder with a particle size

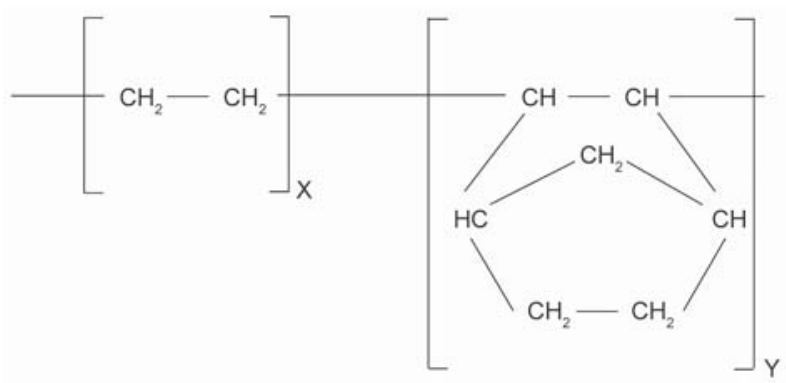

Figure 1. Chemical structure of TOPAS ${ }^{\circledR} 8007$ cyclic olefin copolymer. below $300 \mu \mathrm{m}$. The grinded powder was then mixed with the epoxy base at $50^{\circ} \mathrm{C}$ and $3000 \mathrm{rpm}$ for $1 \mathrm{~h}$. After degassing, the hardener was added into the mixture at a base/hardener relative weight ratio of $100 / 30$, and the resulting mixtures were poured in silicon molds. The curing cycle suggested by the producer of the resin (i.e. $24 \mathrm{~h}$ at $23^{\circ} \mathrm{C}+15 \mathrm{~h}$ at $60^{\circ} \mathrm{C}$ ) was used for the crosslinking of the epoxy matrix. In this way, neat epoxy and epoxy/COC blends with different relative concentrations were prepared. For comparison, a neat COC sample was prepared by hot pressing milled powder at $190^{\circ} \mathrm{C}$ for $10 \mathrm{~min}$ at an applied pressure of $5 \mathrm{MPa}$. Since the healing was performed at elevated temperature and pressure conditions, a separate set of neat epoxy and EP/COC blends were thermally treated at $190^{\circ} \mathrm{C}$ for $1 \mathrm{~h}$, in order to evaluate the healing contribute provided by COC. The temperature selected for the thermal treatment was the same adopted by our group in a previous work on $\mathrm{COC} /$ silica nanocomposites [43] in which $\mathrm{SiO}_{2}$ nanoparticles were homogenously dispersed in the softened COC matrix through melt compounding. The prepared samples were designated as reported in Table 1. In the text, the letter $(u)$ before the name of the samples indicates that it was not treated, while the letter $(t)$ indicates that the thermal treatment was performed.

Representative pictures of the prepared epoxy/COC blends (both untreated and treated) at different COC concentrations are reported in Figure 2. The neat epoxy sample is transparent, whereas samples with COC particles are almost opaque even at the lowest COC content (i.e. 10\%). This is an indication of the relative immiscibility between the two polymer phases. The thermal treatment for 1 hour at $190^{\circ} \mathrm{C}$ affects the color, as all thermally treated samples turned their color to an orange coloration. The change in color is a known effect of thermal aging for epoxy resin systems and it can be attributed to oxidation processes [46]. However, considering that the prepared blends are intended to be used as matrices for composites

Table 1. Composition of epoxy/COC blends.

\begin{tabular}{|l|c|c|c|}
\hline \multicolumn{1}{|c|}{ Materials } & $\begin{array}{c}\text { Epoxy base } \\
{[\mathbf{w t} \% \mathbf{]}}\end{array}$ & $\begin{array}{c}\text { Hardener } \\
{[\mathbf{w t} \% \mathbf{]}}\end{array}$ & $\begin{array}{c}\text { COC } \\
{[\mathbf{w t} \% \mathbf{]}}\end{array}$ \\
\hline EP & 76.9 & 23.1 & - \\
\hline EP/COC10 & 69.2 & 20.8 & 10 \\
\hline EP/COC20 & 61.5 & 18.5 & 20 \\
\hline EP/COC30 & 53.8 & 16.2 & 30 \\
\hline EP/COC40 & 46.0 & 14.0 & 40 \\
\hline COC & - & - & 100 \\
\hline
\end{tabular}




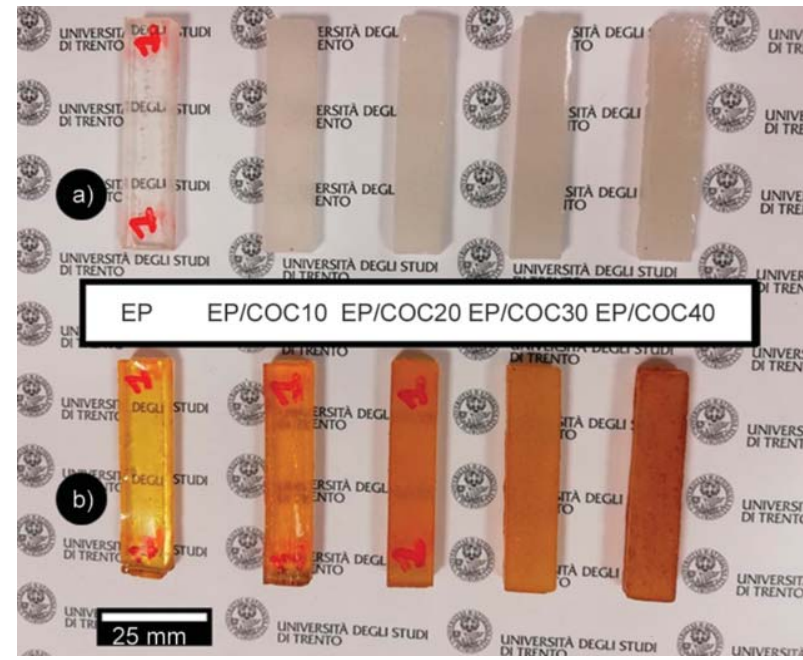

Figure 2. Comparison of the prepared epoxy/COC blends. (a) Untreated and (b) thermally treated samples.

materials, the effects of the COC addition and of the thermal treatment do not represent a relevant aesthetic issue.

\subsection{Experimental techniques}

In order to evaluate the effect of the COC addition on the processability of the resulting blends, rheological measurements on the uncured resin and on the epoxy/COC samples were conducted with a Brookfield RVT coaxial viscometer Model RVT 90658 (AMETEK Brookfield Inc, Middleboro, Massachusetts, USA), equipped with a SC4-21 spindle. For these measurements, $8 \mathrm{~mL}$ of liquid mixtures were poured between the cylinders and tested at a temperature of 23 and $50^{\circ} \mathrm{C}$. The purpose of comparing the viscosity results at two different temperatures was to highlight the advantage of applying a higher temperature during the preparation of the samples, in order to create a homogenous dispersion of COC particles within the liquid epoxy.

The microstructure of the epoxy/COC blends was analyzed through a Zeiss Axiophot optical microscope (Carl Zeiss AG, Oberkochen, Germany), equipped with a Leica DC300 digital camera (Leica Microsystems Ltd., Heerbrugg, Switzerland). The specimens were polished using abrasive grinding papers with grit size P800, P1200, and P4000, sequentially.

Differential scanning calorimetry (DSC) measurements were carried out by using a Mettler DSC30 calorimeter (Mettler-Toledo GmbH, Columbus, Ohio, USA). Three thermal ramps at $10^{\circ} \mathrm{C} \cdot \mathrm{min}^{-1}$ were performed, i.e. first heating stage from 0 to $150^{\circ} \mathrm{C}$, a cooling stage from 150 to $0^{\circ} \mathrm{C}$ and the second heating stage from 0 to $150^{\circ} \mathrm{C}$. The tests were carried out under a nitrogen flow of $100 \mathrm{~mL} \cdot \mathrm{min}^{-1}$. Thermogravimetric analyses (TGA) were carried out through a Mettler TG50 (Mettler-Toledo GmbH, Columbus, Ohio, USA) machine imposing a temperature ramp between 35 and $700^{\circ} \mathrm{C}$ at a heating rate of $10^{\circ} \mathrm{C} \cdot \mathrm{min}^{-1}$ under a constant nitrogen flow of $100 \mathrm{~mL} \cdot \mathrm{min}^{-1}$. In this way, the onset degradation temperature $\left(T_{\text {onset }}\right)$, the temperature associated to a mass loss of $50 \%\left(T_{50 \%}\right)$, the decomposition temperatures of epoxy matrix $\left(T_{\mathrm{dEP}}\right)$ and $\mathrm{COC}\left(T_{\mathrm{dCOC}}\right)$, considered as the temperature of the maximum mass loss rate, and the residual mass at $700^{\circ} \mathrm{C}\left(m_{700}\right)$, were determined.

Quasi-static tensile tests were performed at $23^{\circ} \mathrm{C}$ on ISO 527 1BA dog bone samples (5 $\mathrm{mm}$ wide and $2 \mathrm{~mm}$ thick, gage length of $25 \mathrm{~mm}$ ) by using an Instron ${ }^{\circledR} 4502$ tensile testing machine (ITW Test \& Measurement and Equipment, Norwood, Massachusetts, USA), at a constant crosshead speed of $1 \mathrm{~mm} \cdot \mathrm{min}^{-1}$. For the evaluation of the elastic modulus, the strain was recorded through an Instron 2620601 extensometer, with a gage length of $12.5 \mathrm{~mm}$. According to ISO 527 standard, the elastic modulus was determined as a secant value between strain levels of 0.05 and $0.25 \%$. At least five specimens were tested for each sample.

The evaluation of the fracture toughness of the prepared blends was performed following the procedure described in the ASTM D5045 standard. Single-edge notch bending (SENB) specimens $\left(44 \times 10 \times 5 \mathrm{~mm}^{3}\right)$ were prepared with an initial notch length of approximately $5 \mathrm{~mm}$. The specimens were tested by using an Instron ${ }^{\circledR} 5969$ machine (ITW Test \& Measurement and Equipment, Norwood, Massachusetts, USA) at a crosshead speed of $10 \mathrm{~mm} \cdot \mathrm{min}^{-1}$. At least five specimens were tested for each sample. From the maximum load $\left(P_{\max }\right)$ sustained by the samples, the critical stress intensity factor $\left(K_{\text {Ic }}\right)$ and the critical strain energy release rate $\left(G_{\mathrm{Ic}}\right)$ were determined. In order to determine the healing efficiency in the prepared blends, thermal mending of the broken SENB specimens was performed at $190^{\circ} \mathrm{C}$ for 1 hour. A screw driven mold was used to put in contact the broken parts, applying a compressive stress of $15 \mathrm{MPa}$. To maintain the starting crack within the specimens, the blade used to produce the notch in the virgin samples was properly placed between the broken parts during the mending process. The repaired specimens were tested again under the same conditions, 
and $K_{\mathrm{Ic}}$ and $G_{\mathrm{Ic}}$ parameters of the repaired materials were thus determined. The apparent healing efficiency $(\eta)$ of the prepared samples was thus computed as the ratio between the $K_{\text {Ic }}$ value of the healed samples $\left(K_{\mathrm{Ic}, \mathrm{H}}\right)$ and that of the virgin ones $\left(K_{\mathrm{Ic}, \mathrm{UV}}\right)$, as reported in Equation (1):

$$
\eta=\frac{K_{\mathrm{Ic}, \mathrm{H}}}{K_{\mathrm{Ic}, \mathrm{UV}}}
$$

Considering that the thermal treatment applied to repair the samples was performed at elevated temperature and pressure, the fracture behavior of thermally treated virgin samples was characterized. In this way, a true healing efficiency value $\left(\eta^{\prime}\right)$, calculated as the ratio between the $K_{\text {Ic }}$ value of the healed samples $\left(K_{\mathrm{Ic}, \mathrm{H}}\right)$ and that of the virgin thermally treated ones $\left(K_{\mathrm{Ic}, \mathrm{TV}}\right)$, was computed. Its expression is reported in Equation (2):

$\eta^{\prime}=\frac{K_{\mathrm{Ic}, \mathrm{H}}}{K_{\mathrm{Ic}, \mathrm{TV}}}$

Moreover, this procedure allowed to separate the effects induced by the thermal treatment from that induced by the healing of the COC within the epoxy resin.

In order to better highlight the effectiveness of the adopted healing procedure, optical microscope images showing the crack front after quasi-static flexural tests on fractured and healed samples at a COC amount of 20 and $40 \%$ were taken through a Zeiss Axiophot optical microscope (Carl Zeiss AG, Oberkochen, Germany), equipped with a Leica DC300 digital camera (Leica Microsystems Ltd., Heerbrugg, Switzerland).

Adopting an experimental procedure similar to that utilized in quasi-static flexural tests on notched specimens, the fracture behavior and the healing efficiency of the prepared blends were also determined under impact conditions. At this aim, SENB specimens $\left(44 \times 10 \times 5 \mathrm{~mm}^{3}\right.$ with an initial notch length of about $5 \mathrm{~mm}$ ) were tested with a three point-bending configuration, with a span length of $40 \mathrm{~mm}$ through a CEAST impactor, by using a hammer having a mass of $2.5 \mathrm{~kg}$ and an impact speed of $1 \mathrm{~m} / \mathrm{s}$. From $P_{\max }$ values, the $K_{\text {Ic }}$ of the prepared blends under impact conditions was determined, while the healing efficiency parameters were determined according to the expressions reported in Equation (1) and (2).

Fourier transform infrared spectroscopy (FTIR) tests on the crack plane of SENB specimens were carried out by using a Perkin Elmer Spectrum One FTIRATR analyzer in a scanning interval between 4000 and $650 \mathrm{~cm}^{-1}$.

\section{Results and discussion}

Shear viscosity values of neat epoxy and of the relative epoxy/COC blends at different shear rates, measured at 23 and $50^{\circ} \mathrm{C}$, are reported in Figure 3 . Some points are missing in the plots, because with the adopted equipment it was not possible to measure the high viscosity values of the EP/COC30 sample at $23^{\circ} \mathrm{C}$. For some measurements performed at elevated shear rate, the uncertainty level was too high and the obtained results have been discarded. However, considering that the utilized epoxy system has a relatively long pot life at room temperature (longer than $30 \mathrm{~min}$ ), it is not possible to assume that viscosity measurements were affected by the starting of the crosslinking process in the uncured systems.

Considering the tests performed at the same temperature, it clearly emerges that the viscosity systematically increases with the COC concentration, if the viscosity data at the same shear rate are compared. As expected, an increase in the testing temperature (i.e. $50^{\circ} \mathrm{C}$ ) lead to a slight lowering of the viscosity. In these conditions, the processability of the resulting mixtures is easier. However, the observed increase of the viscosity is not dramatic, at least until a COC concentration of $20 \mathrm{wt} \%$.

Optical microscopy micrographs of the polished surfaces of epoxy/COC blends are shown in Figure 4. The micrographs reveal a rather homogeneous dispersion of COC domains with irregular shape within the epoxy matrix, both for the untreated and the thermally

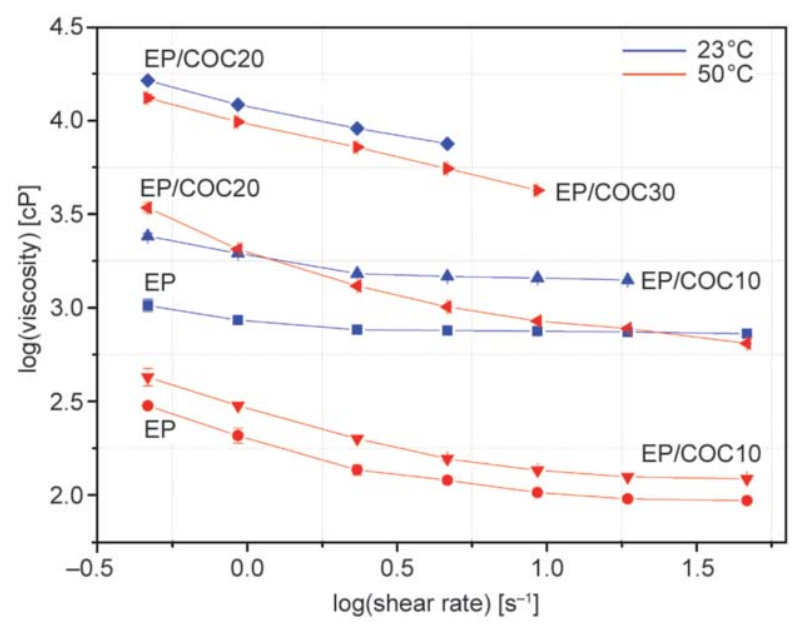

Figure 3. Brookfield viscosity of neat epoxy and uncured epoxy/COC blends at 23 and $50^{\circ} \mathrm{C}$. 

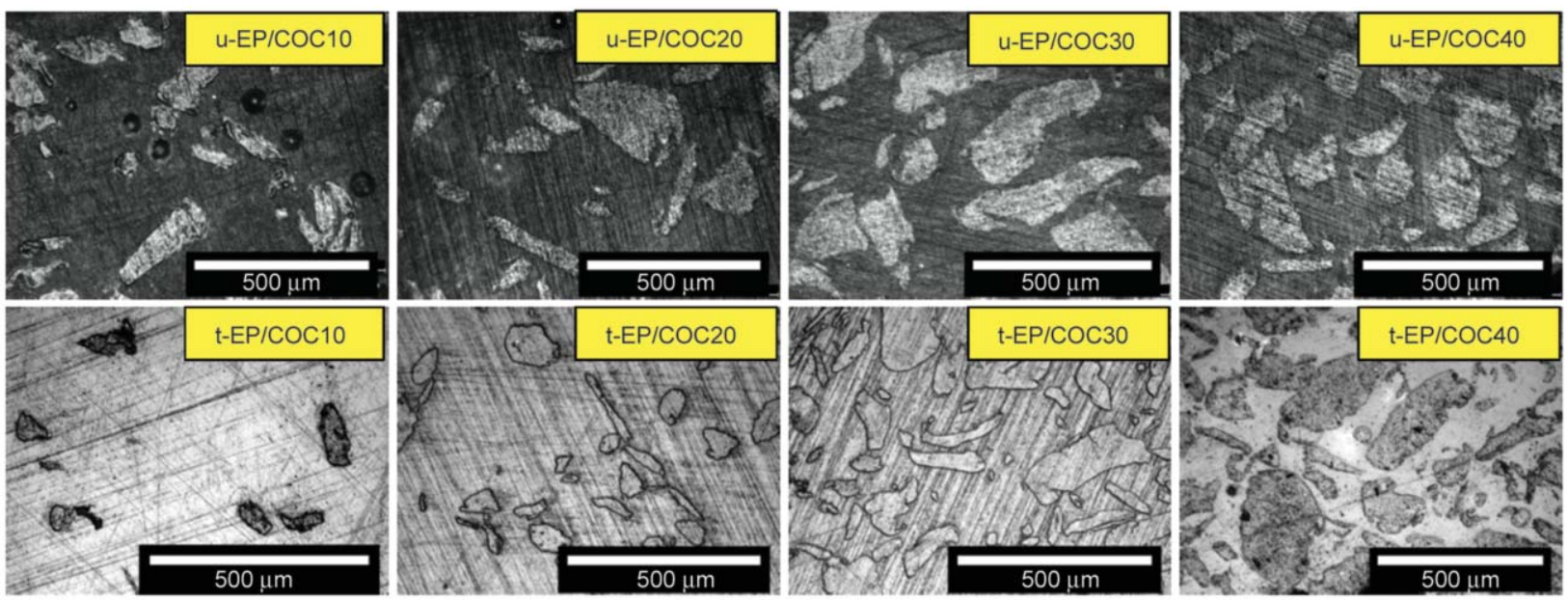

Figure 4. Optical microscope images of the polished surfaces of epoxy/COC blends.

treated samples. No voids or interfacial debonding phenomena can be detected in these images. It is important to underline that the dimension of the COC domains within the epoxy resin seems to be unaffected by the COC amount. In fact, regardless of the COC concentration, for the untreated samples the mean dimension of the COC domains is around $150 \mu \mathrm{m}$, while for the treated samples the mean size of the COC domains is about $120 \mu \mathrm{m}$. It could be hypothesized that the observed decrease of the average dimension of COC domains could be attributed to the softening of the COC phase upon the thermal treatment, but further analyses will be required in the future to better investigate this aspect.

Representative DSC thermograms collected during the first heating stage of the neat matrix and of the epoxy/COC blends are reported in Figure 5, while the glass transition temperatures $\left(T_{\mathrm{g}}\right)$ of the epoxy and the COC phases collected during the first and the second heating stage are summarized in Table 2.
Table 2. Results of DSC tests on neat epoxy, neat COC and relative epoxy/COC blends.

\begin{tabular}{|l|c|c|c|c|}
\hline \multicolumn{1}{|c|}{ Samples } & $\begin{array}{c}\boldsymbol{T}_{\mathbf{g}}{ }^{\mathbf{E} \text { EP }} \\
{\left[{ }^{\circ} \mathbf{C}\right]}\end{array}$ & $\begin{array}{c}\boldsymbol{T}_{\mathbf{g}}{ }^{2} \mathbf{C O C} \\
{\left[{ }^{\circ} \mathbf{C}\right]}\end{array}$ & $\begin{array}{c}\boldsymbol{T}_{\mathbf{g}}{ }^{2} \mathbf{E P} \\
{\left[{ }^{\circ} \mathbf{C}\right]}\end{array}$ & $\begin{array}{c}\boldsymbol{T}_{\mathbf{g}}{ }^{2} \mathbf{C O C} \\
{\left[{ }^{\circ} \mathbf{C}\right]}\end{array}$ \\
\hline u-EP & 84.5 & - & 93.1 & - \\
\hline t-EP & 100.3 & - & 102.1 & - \\
\hline u-EP/COC10 & 86.2 & - & 97.1 & - \\
\hline t-EP/COC10 & 99.8 & - & 101.3 & - \\
\hline u-EP/COC20 & 84.5 & - & 96.1 & - \\
\hline t-EP/COC20 & 99.5 & - & 102.2 & - \\
\hline u-EP/COC30 & 92.0 & - & 98.9 & - \\
\hline t-EP/COC30 & 100.6 & - & 104.5 & - \\
\hline u-EP/COC40 & 86.7 & - & 97.8 & - \\
\hline t-EP/COC40 & 105.2 & - & 105.5 & - \\
\hline u-COC & - & 78.9 & - & 77.8 \\
\hline t-COC & - & 80.9 & - & 79.8 \\
\hline
\end{tabular}

$T_{\mathrm{g}}{ }^{1}{ }_{\mathrm{EP}}=$ glass transition temperature of epoxy (first heating stage) $T_{\mathrm{g}}{ }^{1} \mathrm{COC}=$ glass transition temperature of COC (first heating stage)

$T_{\mathrm{g}}^{2}$ EP $=$ glass transition temperature of epoxy (second heating stage)

$T_{\mathrm{g}}^{2}$ COC $=$ glass transition temperature of COC (second heating stage)
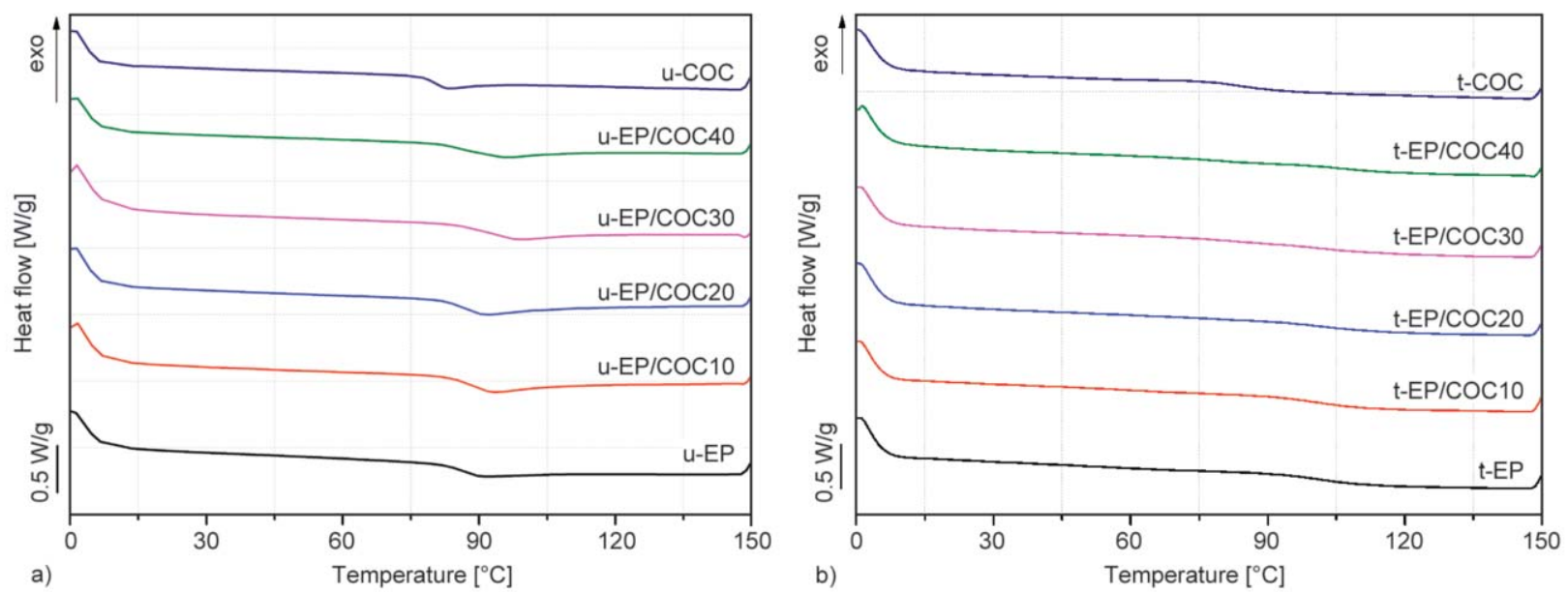

Figure 5. DSC thermograms of neat epoxy, neat COC and relative epoxy/COC blends (first heating stage). (a) Untreated samples and (b) thermally treated samples. 
The glass transition temperature $\left(T_{\mathrm{g}}\right)$ signal associated to the epoxy resin can be clearly detected, while the $T_{\mathrm{g}}$ of the COC phase can be detected only in the thermograms of the neat COC sample. It is interesting to note that in the untreated blends the $T_{\mathrm{g}}$ of the epoxy seems to be substantially unaffected by the COC introduction, with glass transition temperature values around $85-90^{\circ} \mathrm{C}$ (very near to the values indicated in the datasheet by the producer). This is a clear indication of the limited miscibility between the two polymer phases. As expected, the $T_{\mathrm{g}}$ values of the epoxy detected in the second heating stage are systematically higher than those collected during the first heating scan, and the same conclusion can be drawn considering the treated samples. It is clear that this effect is due to the further curing of the epoxy resin, and it could strongly affect both the thermal degradation resistance and the mechanical properties of the resulting blends. On the other hand, the thermal treatment applied on the thermoplastic COC phase does not substantially change its $T_{\mathrm{g}}$, that remains around $80^{\circ} \mathrm{C}$.
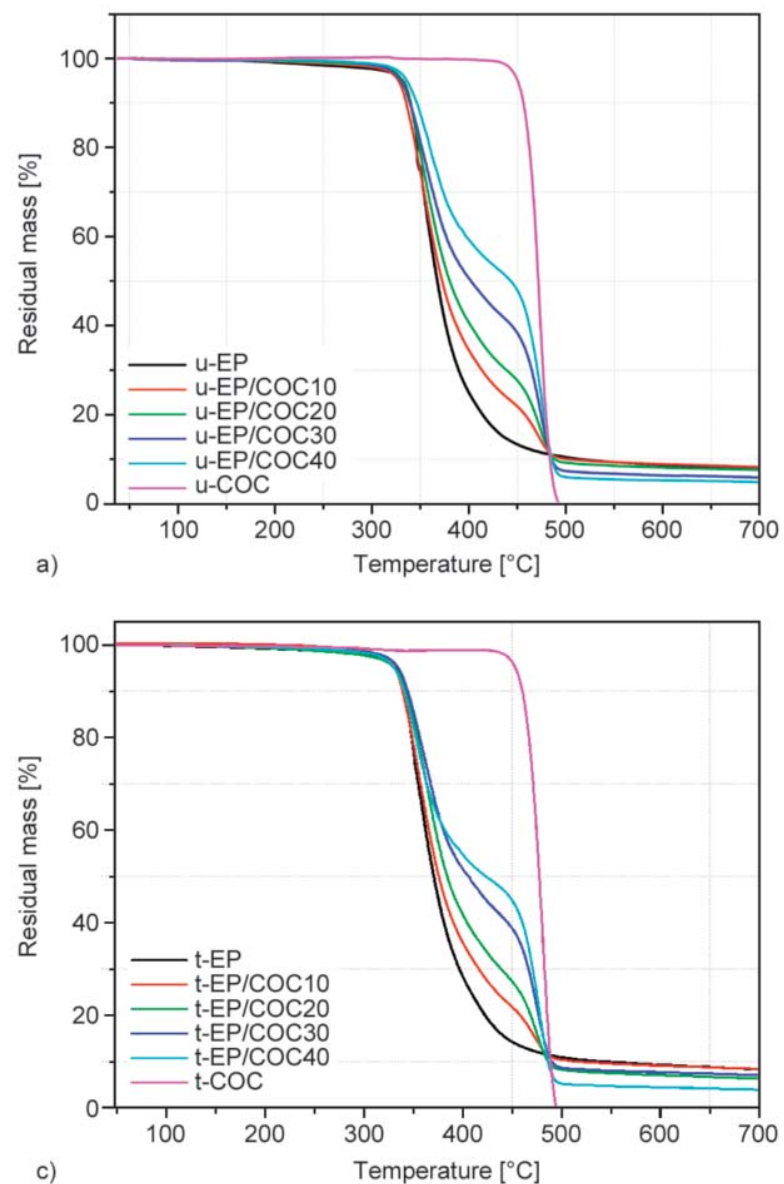

The trends of the residual mass and of the derivative of the mass loss as a function of the testing temperature as measured by thermogravimetric analysis are reported in Figure 6, while the values of the onset degradation temperature $\left(T_{\text {onset }}\right)$, of the temperature associated to a mass loss of the $50 \%\left(T_{50 \%}\right)$, of the degradation temperature of the epoxy $\left(T_{\mathrm{dEP}}\right)$ and the COC $\left(T_{\mathrm{dCOC}}\right)$ phases, and of the residual mass at $700^{\circ} \mathrm{C}\left(m_{700}\right)$ are summarized in Table 3 .

From TGA thermograms it is clearly evident that COC addition produces an interesting increase of the thermal degradation resistance of the samples. In fact, while the $T_{\text {onset }}$ values are practically unaffected by the COC addition, $T_{50 \%}$ are progressively increased upon COC introduction. The COC phase has clearly a superior degradation resistance with respect to the epoxy, and in fact in the derivative mass loss curves the temperature associated to the maximum mass loss rate of the epoxy $\left(T_{\mathrm{dEP}}\right)$ and of the COC $\left(T_{\mathrm{dCOC}}\right)$ can be clearly distinguished. It is also worthwhile to note that the further crosslinking of the resin upon the thermal treatment (proven by
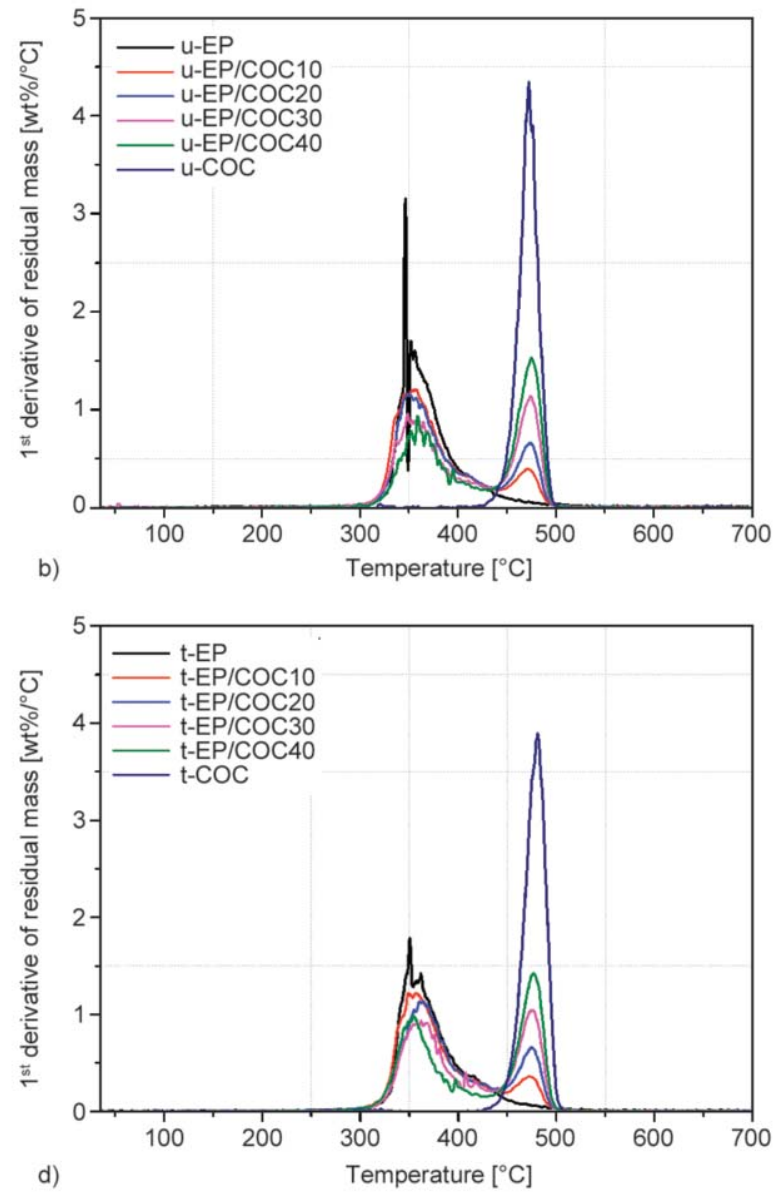

Figure 6. Thermograms of neat epoxy and relative blends by TGA analysis, where (a) and (b) respectively represent the trends of the residual mass and its first derivative of untreated samples, while (c) and (d) represent the trends of the residual mass and its first derivative of thermally treated samples. 
Table 3. Results of TGA tests on neat epoxy, neat COC and relative epoxy/COC blends.

\begin{tabular}{|l|c|c|c|c|c|}
\hline \multicolumn{1}{|c|}{ Samples } & $\begin{array}{c}\boldsymbol{T}_{\text {onset }} \\
{\left[{ }^{\circ} \mathbf{C} \text { ] }\right.}\end{array}$ & $\begin{array}{c}\boldsymbol{T}_{\mathbf{5 0 \%}} \\
{\left[{ }^{\circ} \mathbf{C}\right]}\end{array}$ & $\begin{array}{c}\boldsymbol{T}_{\text {dEP }} \\
{\left[{ }^{\circ} \mathbf{C}\right]}\end{array}$ & $\begin{array}{c}\boldsymbol{T}_{\text {dCOC }} \\
{\left[{ }^{\circ} \mathbf{C}\right]}\end{array}$ & $\begin{array}{c}\boldsymbol{m}_{700} \\
{\left[{ }^{\circ} \mathbf{0}\right]}\end{array}$ \\
\hline u-EP & 334.1 & 367.4 & 345.5 & - & 7.7 \\
\hline t-EP & 335.7 & 371.7 & 352.1 & - & 8.4 \\
\hline u-EP/COC10 & 328.7 & 372.4 & 356.2 & 471.0 & 8.3 \\
\hline t-EP/COC10 & 331.1 & 376.6 & 356.1 & 473.4 & 8.5 \\
\hline u-EP/COC20 & 333.4 & 380.2 & 349.4 & 474.1 & 7.6 \\
\hline t-EP/COC20 & 334.1 & 383.2 & 363.7 & 475.2 & 6.4 \\
\hline u-EP/COC30 & 328.7 & 402.5 & 348.5 & 474.4 & 5.9 \\
\hline t-EP/COC30 & 330.8 & 404.7 & 361.7 & 474.9 & 7.1 \\
\hline u-EP/COC40 & 332.5 & 443.5 & 359.3 & 475.1 & 4.9 \\
\hline t-EP/COC40 & 329.8 & 422.7 & 354.1 & 476.4 & 4.0 \\
\hline u-COC & 450.3 & 471.6 & - & 475.8 & 0.2 \\
\hline t-COC & 457.4 & 477.2 & - & 481.2 & 0.1 \\
\hline
\end{tabular}

$T_{\text {onset }}=$ onset degradation temperature

$T_{50 \%}=$ temperature associated to a mass loss of $50 \%$

$T_{\mathrm{dEP}}=$ decomposition temperature of epoxy matrix

$T_{\mathrm{dCOC}}=$ decomposition temperature of COC

$m_{700}=$ residual mass at $700^{\circ} \mathrm{C}$

DSC) produces a general improvement of the thermal degradation resistance of the samples, with a positive shift of the $T_{50 \%}$ and of the $T_{\mathrm{dEP}}$ values. Once again, this effect is not detectable on neat COC. While at $700^{\circ} \mathrm{C}$ the residual mass for the $\mathrm{COC}$ sample is nearly zero, an increase in COC amount led to a gradual decrease of the $m_{700}$ values. This effect can be ascribed to the incomplete degradation of the thermosetting epoxy phase at elevated temperatures.

Representative stress-strain curves of untreated and treated EP/COC blends are shown in Figure 7, while the trends of the elastic and of the failure properties as a function of the $\mathrm{COC}$ concentration are shown in Figure 8.



It can be observed that the introduction of $\mathrm{COC}$ particles in the blend results in a general reduction of the tensile properties with respect to the neat epoxy, particularly with elevated COC concentration. Even if the observed drop of the elastic modulus in the untreated samples is not so pronounced (from $3.1 \mathrm{GPa}$ of u-EP to $2.3 \mathrm{GPa}$ of u-EP/COC40 sample), a heavier reduction can be observed for the ultimate properties. For instance, in the untreated samples the stress at break decreases from $65 \mathrm{MPa}$ of neat epoxy to $16 \mathrm{MPa}$ for epoxy/COC blend with a COC concentration of $40 \mathrm{wt} \%$. A similar reduction can be detected for the strain at break values. Comparing these trends with the theoretical predictions of the rule of mixture, a negative deviation can be clearly observed. It is also interesting to comment that the thermal treatment produces a systematic increase of the tensile properties, helping thus in the retention of the tensile properties with respect to the untreated epoxy matrix. This effect is probably due to the further crosslinking of the epoxy upon the thermal treatment. It is important to underline that similar trends were obtained also in flexural tests in quasi-static conditions (not reported for the sake of brevity).

The fracture toughness of the prepared blends under quasi-static conditions was then evaluated. Representative load-displacement curves from flexural tests on SENB samples under quasi-static conditions (virgin and healed samples) are collected in Figure 9, while the maximum load $\left(P_{\max }\right)$, critical stress intensity factor $\left(K_{\text {Ic }}\right)$ and critical strain energy release rate $\left(G_{\text {Ic }}\right)$ values of each specimen are numerically summarized in Table 4.

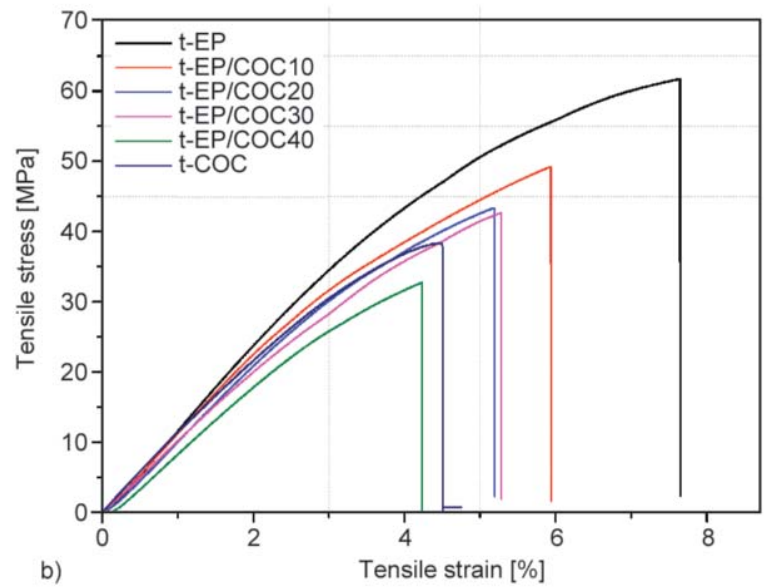

Figure 7. Representative stress-strain curves from quasi-static tensile tests on neat epoxy, neat COC and relative epoxy/COC blends. (a) Untreated samples and (b) thermally treated samples. 

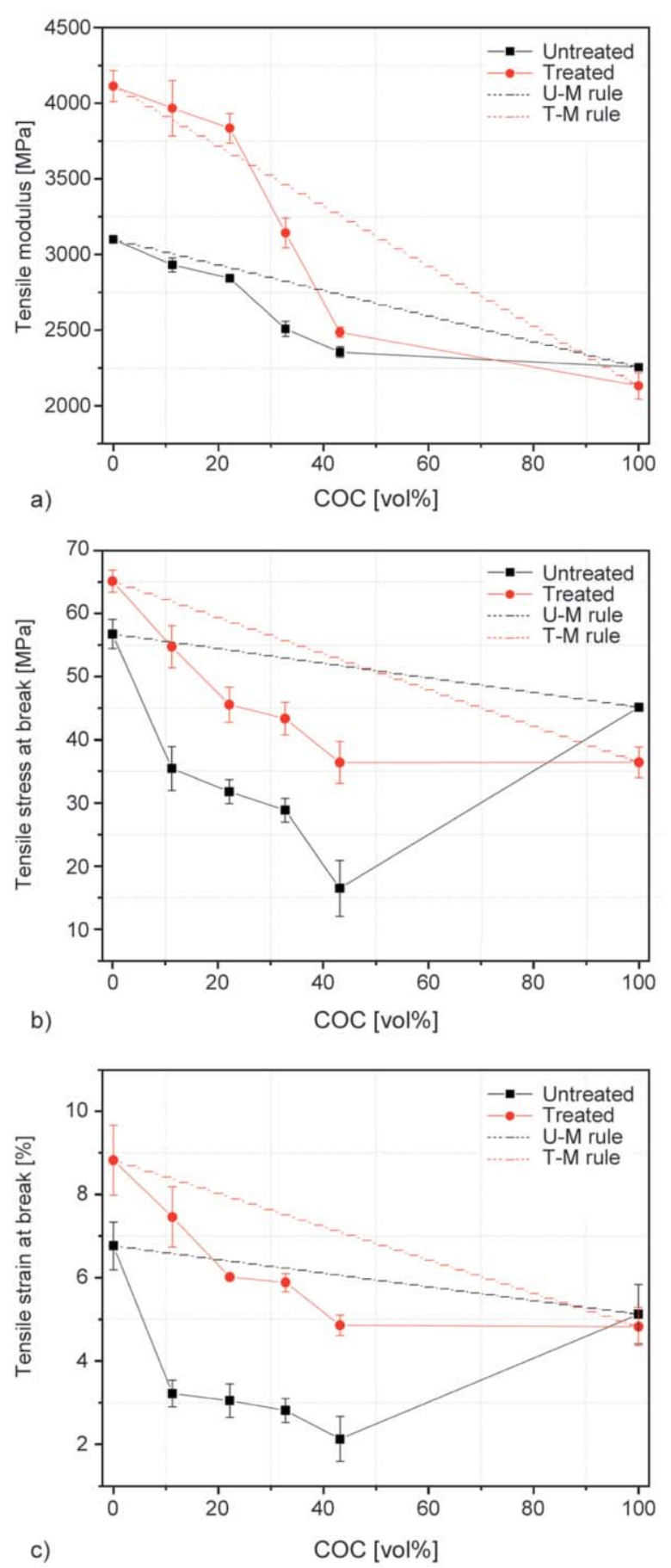

Figure 8. Trends of (a) elastic modulus, (b) stress at break and (c) strain at break as a function of the COC amount for the untreated and thermally treated epoxy/COC blends. Comparison with the rule of mixture (dash-dot lines).

All the prepared blends are characterized by a brittle behavior, with a sudden drop of the load after first failure at $P_{\text {max. }}$ As expected, the maximum load of the u-EP healed samples is rather low compared to that of the corresponding virgin sample. From Figure $9 \mathrm{a}$ it is also clear that a COC amount of $10 \mathrm{wt} \%$ is not sufficient to obtain an efficient healing of the blends, being the $P_{\max }$ of the healed sample considerably lower than that of the virgin one. Increasing the COC amount, a progressive increase of the maximum load of the healed samples can be observed. For instance, $P_{\max }$ value of the u-EP/COC40 healed sample is even higher than that of both the u-EP and the $\mathrm{u}-\mathrm{EP} / \mathrm{COC} 40$ virgin ones. This is a first indication of the effectiveness of COC phase as healing agent within the epoxy matrix. From the results reported in Table 4 it can be seen that both the $K_{\text {Ic }}$ and the $G_{\text {Ic }}$ values of the thermally treated samples are slightly higher than those of the corresponding untreated blends, because of the mechanical properties enhancement due to the further crosslinking of the epoxy resin. It is also interesting to notice that $\mathrm{COC}$ introduction within the epoxy produces a slight increase of the fracture toughness, especially at elevated COC amounts. For instance, $K_{\text {Ic }}$ increases from 0.88 up to $1.13 \mathrm{MPa} \cdot \mathrm{m}^{1 / 2}$ with a COC content of $40 \mathrm{wt} \%$. Therefore, the thermoplastic phase in the epoxy acts as a toughening agent. As mentioned before, the progressive increase of both $K_{\mathrm{Ic}}$ and $G_{\mathrm{Ic}}$ at elevated COC amounts observed for the healed samples indicates an efficient thermal mending capability.

Figure 10 show representative optical microscope images of the crack front in fractured EP and in the healed samples. The EP healed specimen shows a partial healing, and the crack plane originating from the notch is still visible (Figure 10b). In the healed $\mathrm{EP} / \mathrm{COC} 20$ and $\mathrm{EP} / \mathrm{COC} 40$ samples, an almost complete closure of the crack front can be detected. This means that the combined action of the temperature and the pressure allowed the softening of the COC phase and its diffusion within the crack front, allowing thus the healing process.

It is interesting to underline that neat $\mathrm{COC}$ has similar mechanical properties with respect to neat EP (see Figure 7). This probably means that the COC phase present in the crack front is able to sustain similar loads with respect to the virgin epoxy samples, justifying thus the elevated healing capability detected at high COC contents.

The fracture behavior of the prepared blends was evaluated also under impact conditions. Therefore, Charpy impact tests were performed on SENB specimens, and the trends of the maximum load $\left(P_{\max }\right)$ and of the fracture toughness (in terms of $K_{\text {Ic }}$ ) was evaluated. Representative load-displacement from flexural tests on SENB samples under Charpy impact conditions are shown in Figure 11, while in 

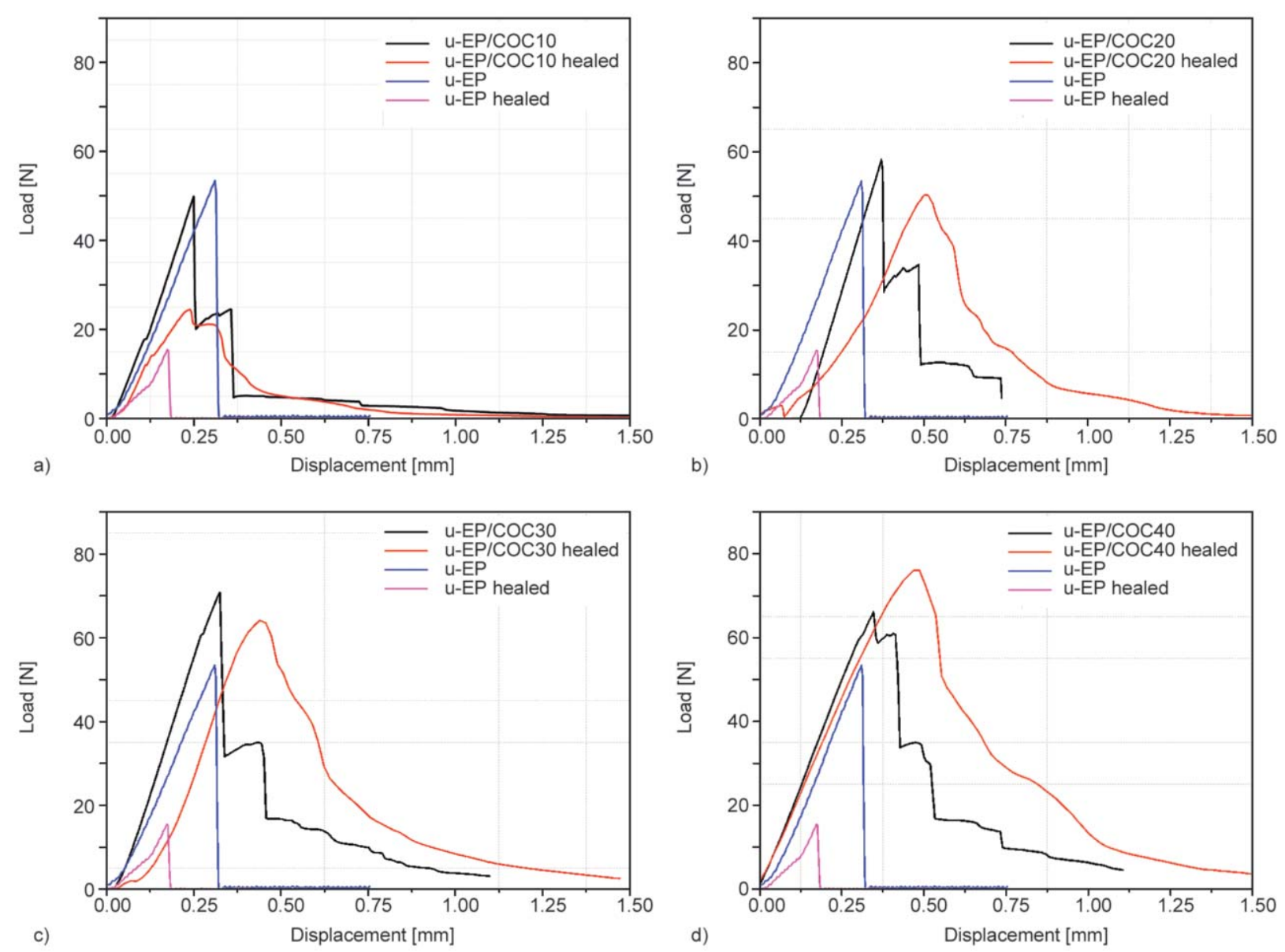

Figure 9. Representative load-displacement curves from flexural tests on SENB samples under quasi-static conditions (virgin and healed samples). Comparison between the fracture behaviour of neat epoxy and (a) u-EP/COC10, (b) uEP/COC20, (c) u-EP/COC30, (d) u-EP/COC40.

Table 4. Results of flexural tests on SENB samples under quasi-static conditions (virgin and healed samples).

\begin{tabular}{|l|c|c|c|c|c|c|}
\hline \multirow{2}{*}{ Samples } & \multicolumn{2}{|c|}{$\begin{array}{c}\boldsymbol{P}_{\text {max }} \\
{[\mathbf{N}]}\end{array}$} & \multicolumn{2}{c|}{$\begin{array}{c}\boldsymbol{K}_{\text {Ic }} \\
{\left[\mathbf{M P a} \cdot \mathbf{m}^{1 / 2}\right]}\end{array}$} & \multicolumn{2}{c|}{$\begin{array}{c}G_{\text {Ic }} \\
{\left[\mathbf{k J} / \mathbf{m}^{2}\right]}\end{array}$} \\
\cline { 2 - 7 } & Virgin samples & Healed samples & Virgin samples & Healed samples & Virgin samples & Healed samples \\
\hline u-EP & $51 \pm 3$ & $13 \pm 6$ & $0.88 \pm 0.03$ & $0.23 \pm 0.09$ & $0.39 \pm 0.07$ & $0.04 \pm 0.02$ \\
\hline t-EP & $53 \pm 2$ & - & $1.01 \pm 0.10$ & - & $0.37 \pm 0.09$ & - \\
\hline u-EP/COC10 & $55 \pm 6$ & $29 \pm 6$ & $0.95 \pm 0.05$ & $0.54 \pm 0.05$ & $0.32 \pm 0.06$ & $0.31 \pm 0.11$ \\
\hline t-EP/COC10 & $57 \pm 2$ & - & $1.02 \pm 0.05$ & - & $0.39 \pm 0.05$ & - \\
\hline u-EP/COC20 & $61 \pm 13$ & $44 \pm 7$ & $1.12 \pm 0.18$ & $0.81 \pm 0.08$ & $0.48 \pm 0.09$ & $0.42 \pm 0.11$ \\
\hline t-EP/COC20 & $62 \pm 2$ & - & $1.22 \pm 0.07$ & - & $0.45 \pm 0.04$ & - \\
\hline u-EP/COC30 & $73 \pm 4$ & $64 \pm 3$ & $1.18 \pm 0.07$ & $1.03 \pm 0.09$ & $0.66 \pm 0.08$ & $0.54 \pm 0.04$ \\
\hline t-EP/COC30 & $75 \pm 11$ & - & $1.29 \pm 0.03$ & - & $0.74 \pm 0.11$ & - \\
\hline u-EP/COC40 & $69 \pm 3$ & $87 \pm 11$ & $1.13 \pm 0.11$ & $1.34 \pm 0.15$ & $0.85 \pm 0.09$ & $1.08 \pm 0.12$ \\
\hline t-EP/COC40 & $96 \pm 17$ & - & $1.51 \pm 0.06$ & - & $1.19 \pm 0.11$ & - \\
\hline
\end{tabular}

$P_{\max }=$ maximum force sustained by the samples

$K_{\mathrm{Ic}}=$ critical stress intensity factor

$G_{\text {Ic }}=$ critical strain energy release rate

Table 5 the values of the maximum load $\left(P_{\max }\right)$ and of the critical stress intensity factor $\left(K_{\text {Ic }}\right)$ are collected. In this case, it was not possible to collect the loaddisplacement curve for the healed EP sample, as the maximum sustained load under impact conditions was too low to be detected. The conclusions are very similar to those reported in quasi-static tests. Even in this case, both the thermal treatment and the $\mathrm{COC}$ addition play a toughening effect on the COC matrix, with a slight increase of both the $P_{\max }$ and the $K_{\text {Ic }}$ 


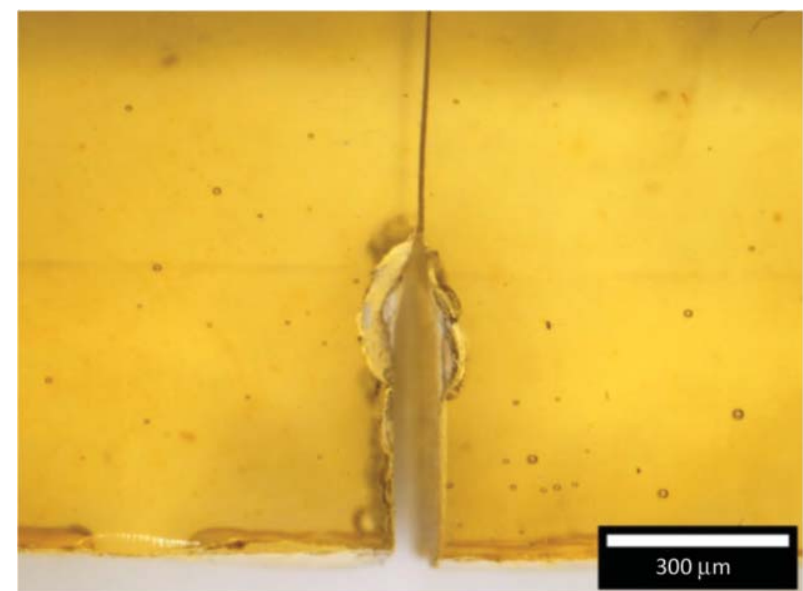

a)

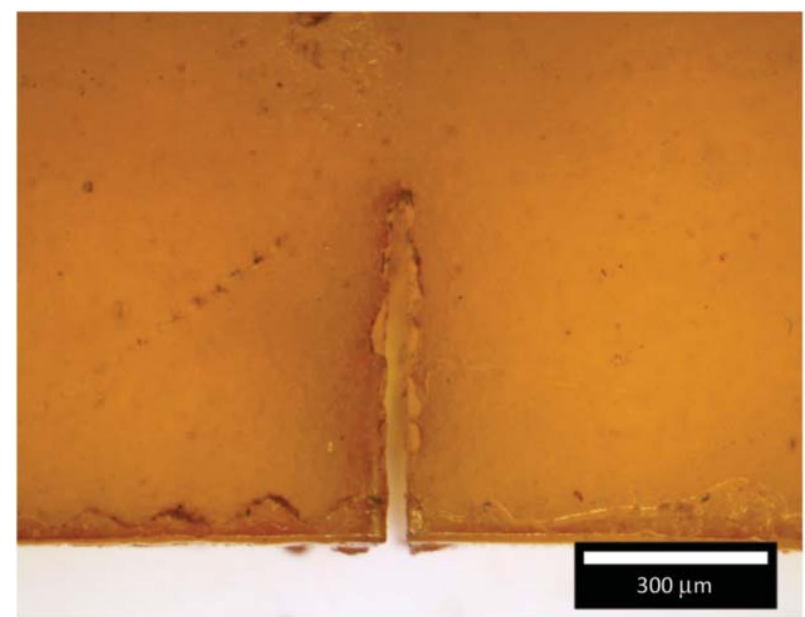

c)

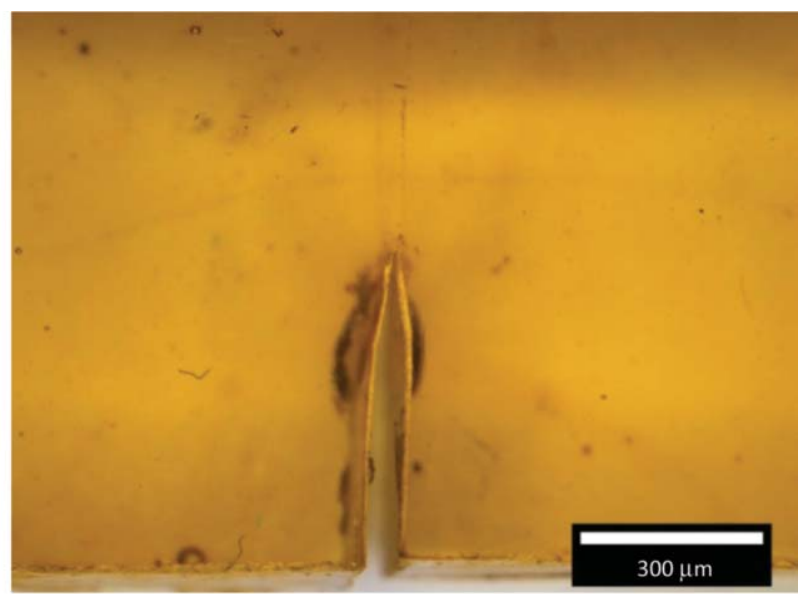

b)

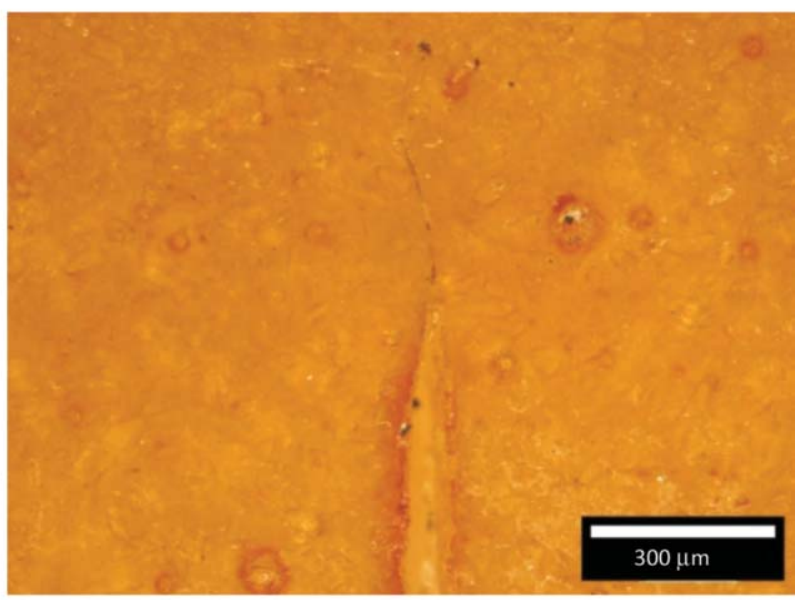

d)

Figure 10. Optical microscope images showing the crack front after quasi-static flexural tests on SENB samples. (a) Fractured EP sample, (b) healed EP, (c) healed EP/COC20 and (d) healed EP/COC40.

values. More interestingly, the maximum load sustained by the samples increases with the COC amount, and for a COC concentration of $30 \mathrm{wt} \%$ it approaches to that of the virgin samples. It seems thus that the effectiveness of the healing process detected at elevated COC concentration in quasi-static conditions could be confirmed also at elevated testing speed.

Finally, it is interesting to evaluate the healing efficiency of the prepared blends. In Table 6 the apparent $(\eta)$ and true $\left(\eta^{\prime}\right)$ healing efficiency values of the neat epoxy and of the relative blends, obtained from flexural tests on SENB samples under quasi-static and impact conditions, are summarized. It is interesting to observe that a general increase of the healing efficiency with the COC amount can be detected, both in quasi-static and Charpy impact tests. For instance, the apparent healing efficiency $(\eta)$ of the $\mathrm{EP} / \mathrm{COC} 40$ is higher than $100 \%$ (i.e. $118 \%$ ), while the true efficiency $\left(\eta^{\prime}\right)$ is $89 \%$. It is important to underline that the healing process of the prepared blends involves not only the diffusion of the softened COC phase within the crack front but also it is affected by the thermal treatment on the epoxy resin (i.e. by the residual curing of the thermosetting phase). Hence, in order to separate these two contributes, a comparison between $\eta$ and $\eta^{\prime}$ values must be made. From Table 6 it is clearly evident that for every blend formulation, the $\eta^{\prime}$ values are systematically lower than the corresponding $\eta$ ones, but the difference is rather limited, considering the standard deviation values associated to these measurements. This means that the healing of the prepared blends is mainly due to the diffusion of the softened COC phase within the crack front, while the increase of the mechanical properties of the epoxy promoted by the thermal treatment (residual cross-linking) plays a secondary role in the mending process. This was confirmed by quasi-static tests performed on thermally treated specimens (see Figure 8).

As far as results of healing efficiency are concerned, it can be hypothesized that the healing mechanism 

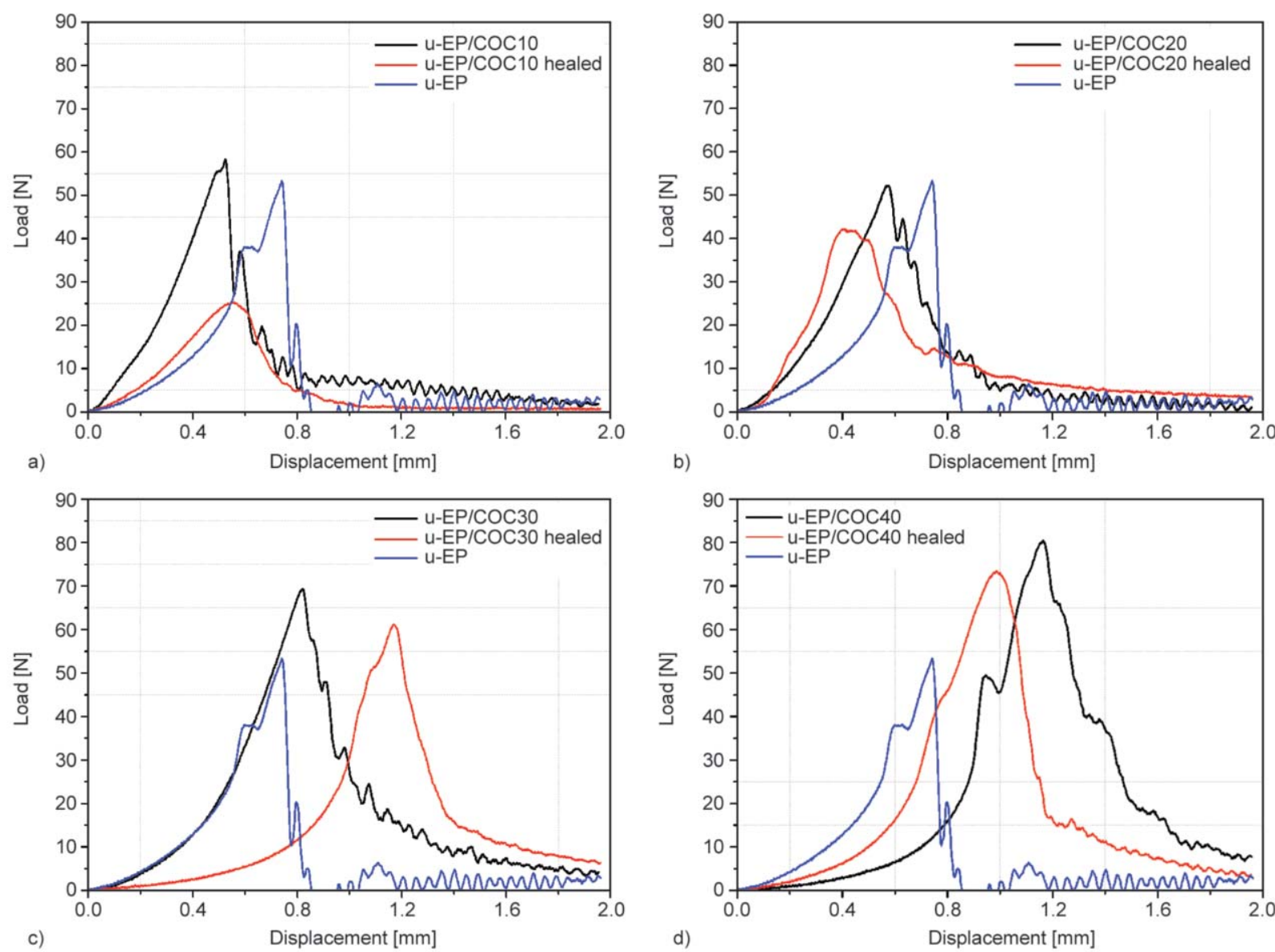

Figure 11. Representative load-displacement curves from flexural tests on SENB samples under Charpy impact conditions (virgin and healed samples). Comparison between the fracture behaviour of $u-E P$ and (a) u-EP/COC10, (b) u$\mathrm{EP} / \mathrm{COC} 20$, (c) u-EP/COC30, (d) u-EP/COC40 samples.

Table 5. Results of flexural tests on SENB samples under Charpy impact conditions (virgin and healed samples).

\begin{tabular}{|l|c|c|c|c|}
\hline \multirow{2}{*}{ Samples } & \multicolumn{2}{|c|}{$\begin{array}{c}\text { P } \\
\text { [N] }\end{array}$} & \multicolumn{2}{c|}{$\boldsymbol{K}_{\text {Ic }}$} \\
\cline { 2 - 5 } & Virgin samples & Healed samples & Virgin samples & Healed samples \\
\hline u-EP & $50.0 \pm 1.0$ & - & $0.83 \pm 0.03$ & - \\
\hline t-EP & $51.0 \pm 2.0$ & - & $0.97 \pm 0.04$ & $0.88 \pm 0.02$ \\
\hline u-EP/COC10 & $55.0 \pm 7.0$ & $27.0 \pm 2.0$ & $0.99 \pm 0.03$ & - \\
\hline t-EP/COC10 & $57.0 \pm 2.0$ & - & $1.02 \pm 0.11$ & $0.91 \pm 0.05$ \\
\hline u-EP/COC20 & $57.0 \pm 12.0$ & $49.0 \pm 7.0$ & $1.10 \pm 0.07$ & - \\
\hline t-EP/COC20 & $58.0 \pm 5.0$ & - & $1.17 \pm 0.02$ & $1.11 \pm 0.06$ \\
\hline u-EP/COC30 & $72.0 \pm 3.0$ & $68.0 \pm 3.0$ & $1.20 \pm 0.17$ & - \\
\hline t-EP/COC30 & $75.0 \pm 11.0$ & - & $1.10 \pm 0.14$ & $1.13 \pm 0.11$ \\
\hline u-EP/COC40 & $69.0 \pm 11.0$ & $67.0 \pm 10.0$ & $1.16 \pm 0.01$ & - \\
\hline t-EP/COC40 & $71.0 \pm 6.0$ & - & & \\
\hline
\end{tabular}

in this system involves the migration of COC at the crack face, which would diffuse itself in the crack plane under temperature and pressure. To verify this hypothesis, FTIR spectroscopy was performed on the crack face of EP/COC specimens after the healing process, and the resulting spectrum was compared with that of the u-EP and of u-COC specimens. In Figure 12 the FTIR spectrum of EP/COC30 sample is presented and compared with that $\mathrm{u}-\mathrm{EP}$ and $\mathrm{u}-$ COC specimens. The spectrum of $\mathrm{EP} / \mathrm{COC} 30$ was taken from the crack face of SENB specimen which was mended at $190^{\circ} \mathrm{C}$ and 1 hour, in order to verify the diffusion of $\mathrm{COC}$ on the crack plane. Looking carefully at Figure 12, it can be seen that u-COC shows a couple of double peaks in the functional group region, i.e. $2943-2922$ and $2866-2852 \mathrm{~cm}^{-1}$ 
Table 6. Apparent $(\eta)$ and true $\left(\eta^{\prime}\right)$ healing efficiency of neat epoxy and relative blends from flexural tests on SENB samples under quasi-static and impact conditions.

\begin{tabular}{|l|c|c|c|c|}
\hline \multirow{2}{*}{ Samples } & \multicolumn{2}{|c|}{ Quasi-static tests } & \multicolumn{2}{c|}{ Impact tests } \\
\cline { 2 - 5 } & $\begin{array}{c}\boldsymbol{\eta} \\
{[\%]}\end{array}$ & $\begin{array}{c}\boldsymbol{\eta}^{\prime} \\
{[\%]}\end{array}$ & $\begin{array}{c}\boldsymbol{\eta} \\
{[\%]}\end{array}$ & $\begin{array}{c}\boldsymbol{\eta}^{\prime} \\
{[\%]}\end{array}$ \\
\hline EP & $26.2 \pm 10.3$ & $22.8 \pm 9.2$ & - & - \\
\hline EP/COC10 & $56.9 \pm 6.1$ & $52.9 \pm 5.6$ & $51.2 \pm 3.6$ & $45.5 \pm 3.3$ \\
\hline EP/COC20 & $72.3 \pm 13.7$ & $66.4 \pm 7.6$ & $89.2 \pm 10.7$ & $82.7 \pm 6.9$ \\
\hline EP/COC30 & $87.3 \pm 9.2$ & $79.8 \pm 7.2$ & $95.0 \pm 5.3$ & $92.5 \pm 14.1$ \\
\hline EP/COC40 & $118.6 \pm 17.6$ & $88.7 \pm 10.5$ & $102.7 \pm 16.5$ & $97.4 \pm 9.5$ \\
\hline
\end{tabular}

intervals. These two absorption peaks refer to the $\mathrm{CH}$ stretching [47], and, even if with low intensity, these peaks can be detected in the EP/COC30 spectrum. Concurrently, these peaks are not present in the uEP spectrum. Therefore, this proves the presence of the COC phase in the crack plane of the EP/COC30 specimen after the thermal mending process.

On the basis of the obtained results, it can be hypothesized that at elevated temperature $\left(190^{\circ} \mathrm{C}\right), \mathrm{COC}$ particles present in the crack plane can be softened and can diffuse in the crack space, under the influence of the applied pressure, hence mending the

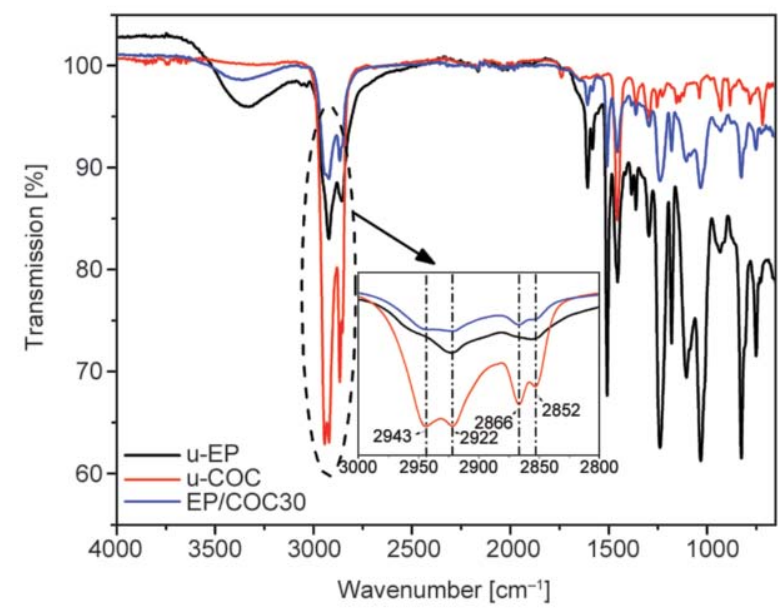

Figure 12. FTIR spectra of $\mathrm{u}-\mathrm{EP}, \mathrm{u}-\mathrm{COC}$ healing agent and the crack face of $\mathrm{EP} / \mathrm{COC} 30$ after healing process $\left(190^{\circ} \mathrm{C}\right.$ and $\left.1 \mathrm{~h}\right)$. damage. As represented in a schematic diagram in Figure 13, the prepared EP/COC systems consist of COC particles uniformly distributed in the epoxy matrix. Under suitable conditions, it can be assumed that a crack would propagate through the epoxy matrix and preferably at the interface between the epoxy and $\mathrm{COC}$ as the crack passes near the particles. In this situation, the uniform compressive pressure applied perpendicular to the crack plane would join the crack front of the two pieces. The application of an elevated temperature $\left(190^{\circ} \mathrm{C}\right)$ leads the COC particles to soften and diffuse uniformly in the crack space. The diffusion of COC can be associated to the softening of the epoxy matrix, which would favorably bond with the diffused COC phase, hence promoting the mending process.

It is certainly worthwhile to compare the healing performances obtained in this paper with those reported in literature on similar epoxy systems. At this aim, in Table 7 a summary of the healing performances obtained in previous papers on epoxy systems is reported. From this table it can be noticed that in the paper of Yao et al. [48] and of Hayes et al. [24] rather low healing efficiency values are reported. On the other hand, Karger-Kocsis [49] used PCL as a healing agent with different epoxy types, finding that the dispersion of the PCL phase within the epoxy matrix depends on the type of epoxy used. A semi-penetrating network structure of PCL in the epoxy led to higher healing efficiency values (i.e. up to $80 \%$ ). With a similar system, Luo et al. [36] demonstrated that it is possible to obtain efficiency levels even higher than $100 \%$ increasing the healing temperature up to $190^{\circ} \mathrm{C}$ (i.e. the same used in the present work). Even in that paper, it was shown that the elevated thermal mending capability of epoxy/PCL blends was not due to any residual curing of epoxy but rather than to the PCL inclusion.

Therefore, it can be concluded that the results obtained in the present paper are comparable with the

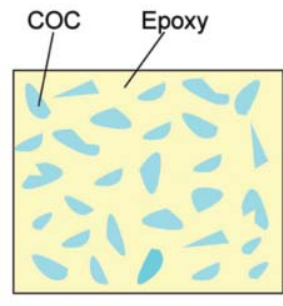

Virgin specimen

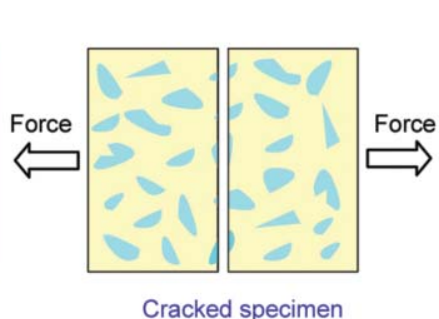

Cracked specimen

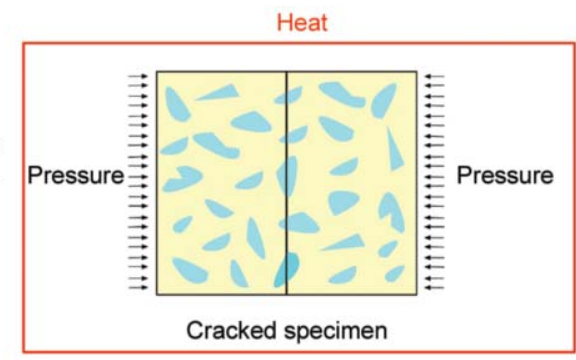

Crack healing under heat and pressure

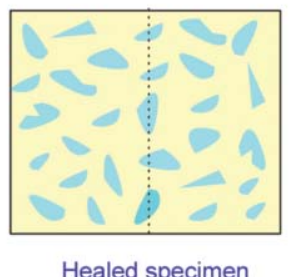

Healed specimen

Figure 13. Schematic diagram of healing process in the prepared EP/COC blends. 
Table 7. Summary of the healing performances obtained in previous papers on epoxy systems.

\begin{tabular}{|c|c|c|c|c|c|}
\hline Year & Author & Healing agent & $\begin{array}{c}\text { Healing temperature } \\
{\left[{ }^{\circ} \mathrm{C}\right]}\end{array}$ & $\begin{array}{c}\text { Healing efficiency } \\
{[\%]}\end{array}$ & Ref. \\
\hline 2007 & Hayes et al. & polybisphenol-A-co-epichlorohydrin & 140 & 65 & [24] \\
\hline 2009 & Luo et al. & poly(e-caprolactone) & 190 & $>100$ & [36] \\
\hline 2009 & Meure et al. & polyethylene-co-methacrylic acid (EMAA) & 150 & 85 & [34] \\
\hline 2016 & Yao et al. & poly(e-caprolactone) & 80 & 45 & [48] \\
\hline 2016 & Cohades et al. & poly(e-caprolactone) & 150 & $>70$ & {$[50]$} \\
\hline 2016 & Karger-Kocsis & poly(e-caprolactone) & 80 & $>80$ & [49] \\
\hline
\end{tabular}

best examples of mendable thermoplastic/epoxy systems developed so far in literature. Attempts to evaluate the effectiveness of these blends as matrix for fiber-reinforced polymers with thermally mending capabilities will be performed in the future.

\section{Conclusions}

For the first time, epoxy/cyclic olefin copolymer blends were prepared and thermo-mechanically characterized, with the aim to evaluate their thermal mending potential. COC domains resulted to be rather homogenously dispersed within the polymer matrix, without any appreciable increase of the matrix porosity. Introduction of the thermoplastic phase within the epoxy matrix positively contributed to the thermal degradation resistance of the samples, while the tensile mechanical properties were worsened at elevated COC amounts (an elastic modulus drop of the $25 \%$ and a stress at break decrease of the $75 \%$ were detected with a COC amount of $40 \mathrm{wt} \%$ ). The thermal treatment applied on the healed samples positively contributed to the retention of the tensile properties of the pristine matrix. Flexural tests on notched specimens demonstrated that $\mathrm{COC}$ addition progressively increased the fracture toughness (i.e. $K_{\mathrm{Ic}}$ ) of the blends, both under quasi-static and Charpy impact conditions. Quite noticeably, a progressive increase of the healing efficiency with the COC concentration was detected. At a COC content of $40 \mathrm{wt} \%$, true efficiency values near to $100 \%$ were found. It could be therefore concluded that an amorphous thermoplastic matrix like COC can be successfully used as healing agent for thermosetting epoxy matrix.

\section{Acknowledgements}

We deeply acknowledge prof. Joseph Karger-Kocsis for his inspiring contribution. In fact, the idea behind this work emerged during the period he spent at the University of Trento as a visiting professor in May 2018. This research activity has been financed by Fondazione Cassa di Risparmio di Trento e Rovereto (CARITRO, Grant number 2017.0389) within the project 'Development of self-sensing/self healing structural composites using graphene treated fibers'. The work has been also supported by the National Interuniversitary Consortium of Materials Science and Technology (INSTM). Mr. Thierry Hermann Tatsayem is gratefully acknowledged for his support to the experimental work.

\section{References}

[1] Yang Y., Boom R., Irion B., van Heerden D-J., Kuiper P., de Wit H.: Recycling of composite materials. Chemical Engineering and Processing-Process Intensification, 51, 53-68 (2012). https://doi.org/10.1016/j.cep.2011.09.007

[2] Yuan C., Xie C., Li L., Zhang F., Gubanski S. M.: Ultrasonic phased array detection of internal defects in composite insulators. IEEE Transactions on Dielectrics and Electrical Insulation, 23, 525-531 (2016). https://doi.org/10.1109/TDEI.2015.005225

[3] Pedrazzoli D., Dorigato A., Pegoretti A.: Monitoring the mechanical behaviour of electrically conductive polymer nanocomposites under ramp and creep conditions. Journal of Nanoscience and Nanotechnology, 12, 4093-4102 (2012).

https://doi.org/10.1166/jnn.2012.6219

[4] Pedrazzoli D., Dorigato A., Pegoretti A.: Monitoring the mechanical behavior under ramp and creep conditions of electrically conductive polymer composites. Composites Part A: Applied Science and Manufacturing, 43, 1285-1292 (2012).

https://doi.org/10.1016/j.compositesa.2012.03.019

[5] Dorigato A., Pegoretti A.: Flexural and impact behaviour of carbon/basalt fibers hybrid laminates. Journal of Composite Materials, 48, 1121-1130 (2014). https://doi.org/10.1177/0021998313482158 
[6] Reifsnider K., Schulte K., Duke J.: Long-term fatigue behavior of composite materials. in 'Long-term behavior of composites' (eds.: O’Brien T.) ASTM International, West Conshohocken, 136-159 (1983).

https://doi.org/10.1520/STP31820S

[7] White S. R., Sottos N. R., Geubelle P. H., Moore J. S., Kessler M. R., Sriram S. R., Brown E. N., Viswanathan S.: Autonomic healing of polymer composites. Nature, 409, 794-797 (2001). https://doi.org/10.1038/35057232

[8] Patel A. J., Sottos N. R., Wetzel E. D., White S. R.: Autonomic healing of low-velocity impact damage in fiber-reinforced composites. Composites Part A: Applied Science and Manufacturing, 41, 360-368 (2010). https://doi.org/10.1016/j.compositesa.2009.11.002

[9] Norris C. J., Meadway G. J., O’Sullivan M. J., Bond I. P., Trask R. S.: Self-healing fibre reinforced composites via a bioinspired vasculature. Advanced Functional Materials, 21, 3624-3633 (2011). https://doi.org/10.1002/adfm.201101100

[10] Karger-Kocsis J., Kéki S.: Review of progress in shape memory epoxies and their composites. Polymers, 10, 34/1-34/38 (2017). https://doi.org/10.3390/polym10010034

[11] Bergman S. D., Wudl F.: Mendable polymers. Journal of Materials Chemistry, 18, 41-62 (2008). https://doi.org/10.1039/b713953p

[12] Garcia S. J., Fischer H. R.: Self-healing polymer systems: Properties, synthesis and applications. in 'Smart polymers and their applications' (eds.: Aguilar M. R., San Román J.) Woodhead, New York, 271-298 (2014). https://doi.org/10.1533/9780857097026.1.271

[13] Chen X., Dam M. A., Ono K., Mal A., Shen H., Nutt S. R., Sheran K., Wudl F.: A thermally re-mendable crosslinked polymeric material. Science, 295, 1698-1702 (2002).

https://doi.org/10.1126/science.1065879

[14] Zhang Y., Broekhuis A. A., Picchioni F.: Thermally selfhealing polymeric materials: The next step to recycling thermoset polymers? Macromolecules, 42, 1906-1912 (2009).

https://doi.org/10.1021/ma8027672

[15] Kavitha A. A., Singha N. K.: 'Click chemistry' in tailor-made polymethacrylates bearing reactive furfuryl functionality: A new class of self-healing polymeric material. ACS Applied Materials and Interfaces, 1, 1427 1436 (2009). https://doi.org/10.1021/am900124c

[16] Canary S. A., Stevens M. P.: Thermally reversible crosslinking of polystyrene via the furan-maleimide DielsAlder reaction. Journal of Polymer Science Part A: Polymer Chemistry, 30, 1755-1760 (1992). https://doi.org/10.1002/pola.1992.080300829

[17] Liu Y-L., Hsieh C-Y., Chen Y-W.: Thermally reversible cross-linked polyamides and thermo-responsive gels by means of Diels-Alder reaction. Polymer, 47, 25812586 (2006).

https://doi.org/10.1016/j.polymer.2006.02.057
[18] Magana S., Zerroukhi A., Jegat C., Mignard N.: Thermally reversible crosslinked polyethylene using DielsAlder reaction in molten state. Reactive and Functional Polymers, 70, 442-448 (2010).

https://doi.org/10.1016/j.reactfunctpolym.2010.04.007

[19] Tian Q., Rong M. Z., Zhang M. Q., Yuan Y. C.: Synthesis and characterization of epoxy with improved thermal remendability based on Diels-Alder reaction. Polymer International, 59, 1339-1345 (2010).

https://doi.org/10.1002/pi.2872

[20] Pratama P. A., Peterson A. M., Palmese G. R.: The role of maleimide structure in the healing of furan-functionalized epoxy-amine thermosets. Polymer Chemistry, 4, 5000-5006 (2013). https://doi.org/10.1039/c3py00084b

[21] Bai N., Saito K., Simon G. P.: Synthesis of a diamine cross-linker containing Diels-Alder adducts to produce self-healing thermosetting epoxy polymer from a widely used epoxy monomer. Polymer Chemistry, 4, 724730 (2013).

https://doi.org/10.1039/c2py20611k

[22] Du P., Liu X., Zheng Z., Wang X., Joncheray T., Zhang Y.: Synthesis and characterization of linear self-healing polyurethane based on thermally reversible Diels-Alder reaction. RSC Advances, 3, 15475-15482 (2013).

https://doi.org/10.1039/C3RA42278J

[23] Pingkarawat K., Wang C. H., Varley R. J., Mouritz A. P.: Mechanical properties of mendable composites containing self-healing thermoplastic agents. Composites Part A: Applied Science and Manufacturing, 65, 10-18 (2014). https://doi.org/10.1016/j.compositesa.2014.05.015

[24] Hayes S. A., Jones F. R., Marshiya K., Zhang W.: A Self-healing thermosetting composite material. Composites Part A: Applied Science and Manufacturing, 38, 1116-1120 (2007).

https://doi.org/10.1016/j.compositesa.2006.06.008

[25] Hayes S. A., Zhang W., Branthwaite M., Jones F. R.: Self-healing of damage in fibre-reinforced polymer-matrix composites. Journal of the Royal Society Interface, 4, 381-387 (2007). https://doi.org/10.1098/rsif.2006.0209

[26] Jones A. R., Watkins C. A., White S. R., Sottos N. R.: Self-healing thermoplastic-toughened epoxy. Polymer, 74, 254-261 (2015). https://doi.org/10.1016/j.polymer.2015.07.028

[27] van Gemert G. M. L., Peeters J. W., Söntjens S. H. M., Janssens H. M., Bosman A. W.: Self-healing supramolecular polymers in action. Macromolecular Chemistry and Physics, 213, 234-242 (2012). https://doi.org/10.1002/macp.201100559

[28] Rodriguez E. D., Luo X., Mather P. T.: Linear/network poly( $\varepsilon$-caprolactone) blends exhibiting shape memory assisted self-healing (SMASH). ACS Applied Materials and Interfaces, 3, 152-161 (2011). https://doi.org/10.1021/am101012c 
[29] Luo X., Mather P. T.: Shape memory assisted self-healing coating. ACS Macro Letters, 2, 152-156 (2013). https://doi.org/10.1021/mz400017x

[30] Birjandi Nejad H., Robertson J. M., Mather P. T.: Interwoven polymer composites via dual-electrospinning with shape memory and self-healing properties. MRS Communications, 5, 211-221 (2015).

https://doi.org/10.1557/mrc.2015.39

[31] Wang C. H., Sidhu K., Yang T., Zhang J., Shanks R.: Interlayer self-healing and toughening of carbon fibre/ epoxy composites using copolymer films. Composites Part A: Applied Science and Manufacturing, 43, 512518 (2012).

https://doi.org/10.1016/j.compositesa.2011.11.020

[32] Pingkarawat K., Wang C. H., Varley R. J., Mouritz A. P.: Self-healing of delamination cracks in mendable epoxy matrix laminates using poly[ethylene-co-(methacrylic acid)] thermoplastic. Composites Part A: Applied Science and Manufacturing, 43, 1301-1307 (2012).

https://doi.org/10.1016/j.compositesa.2012.03.010

[33] Dell'Olio C., Yuan Q., Varley R. J.: Epoxy/poly(ethylene-co-methacrylic acid) blends as thermally activated healing agents in an epoxy/amine network. Macromolecular Materials and Engineering, 300, 70-79 (2015). https://doi.org/10.1002/mame.201400126

[34] Meure S., Wu D. Y., Furman S.: Polyethylene-comethacrylic acid healing agents for mendable epoxy resins. Acta Materialia, 57, 4312-4320 (2009). https://doi.org/10.1016/j.actamat.2009.05.032

[35] Pingkarawat K., Bhat T., Craze D. A., Wang C. H., Varley R. J., Mouritz A. P.: Healing of carbon fibre-epoxy composites using thermoplastic additives. Polymer Chemistry, 4, 5007-5015 (2013). https://doi.org/10.1039/c3py00459g

[36] Luo X., Ou R., Eberly D. E., Singhal A., Viratyaporn W., Mather P. T.: A thermoplastic/thermoset blend exhibiting thermal mending and reversible adhesion. ACS Applied Materials and Interfaces, 1, 612-620 (2009). https://doi.org/10.1021/am8001605

[37] Fejos M., Molnar K., Karger-Kocsis J.: Epoxy/polycaprolactone systems with triple-shape memory effect: Electrospun nanoweb with and without graphene versus co-continuous morphology. Materials, 6, 4489-4504 (2013). https://doi.org/10.3390/ma6104489

[38] Yang T., Wang C. H., Zhang J., He S., Mouritz A. P.: Toughening and self-healing of epoxy matrix laminates using mendable polymer stitching. Composites Science and Technology, 72, 1396-1401 (2012). https://doi.org/10.1016/j.compscitech.2012.05.012

[39] Wei H., Yao Y., Liu Y., Leng J.: A dual-functional polymeric system combining shape memory with self-healing properties. Composites Part B: Engineering, 83, 7 13 (2015).

https://doi.org/10.1016/j.compositesb.2015.08.019
[40] Pegoretti A., Dorigato A., Biani A., Slouf M.: Cyclic olefin copolymer-silica nanocomposites foams. Journal of Materials Science, 51, 3907-3916 (2016).

https://doi.org/10.1007/s10853-015-9710-9

[41] Dorigato A., Canclini P., Unterberger S. H., Pegoretti A.: Phase changing nanocomposites for low temperature thermal energy storage and release. Express Polymer Letters, 11, 738-752 (2017).

https://doi.org/10.3144/expresspolymlett.2017.71

[42] Dorigato A., Biani A., Bonani W., Pegoretti A.: Thermoelectrical behaviour of cyclic olefin copolymer/exfoliated graphite nanoplatelets nanocomposites foamed through supercritical carbon dioxide. Journal of Cellular Plastics, 55, 263-282 (2019).

https://doi.org/10.1177/0021955x19839733

[43] Dorigato A., Pegoretti A., Fambri L., Slouf M., Kolarik J.: Cycloolefin copolymer/fumed silica nanocomposites. Journal of Applied Polymer Science, 119, 33933402 (2011).

https://doi.org/10.1002/app.32988

[44] Dorigato A., Pegoretti A., Fambri L., Lonardi C., Šlouf M., Kolařik J.: Linear low density polyethylene/cycloolefin copolymer blends. Express Polymer Letters, 5, 23-37 (2011). https://doi.org/10.3144/expresspolymlett.2011.4

[45] Biani A., Dorigato A., Bonani W., Slouf M., Pegoretti A.: Mechanical behaviour of cyclic olefin copolymer/exfoliated graphite nanoplatelets nanocomposites foamed by supercritical carbon dioxide. Express Polymer Letters, 10, 977-989 (2016).

https://doi.org/10.3144/expresspolymlett.2016.91

[46] Krauklis A. E., Echtermeyer A. T.: Mechanism of yellowing: Carbonyl formation during hygrothermal aging in a common amine epoxy. Polymers, 10, 1017/11017/15 (2018).

https://doi.org/10.3390/polym10091017

[47] Jena R. K., Yue C. Y., Anand L.: Improvement of thermal bond strength and surface properties of cyclic olefin copolymer (COC) based microfluidic device using the photo-grafting technique. Sensors and Actuators B: Chemical, 157, 518-526 (2011).

https://doi.org/10.1016/j.snb.2011.05.012

[48] Yao Y., Wang J., Lu H., Xu B., Fu Y., Liu Y., Leng J.: Thermosetting epoxy resin/thermoplastic system with combined shape memory and self-healing properties. Smart Materials and Structures, 25, 015021/1-015021/9 (2016).

https://doi.org/10.1088/0964-1726/25/1/015021

[49] Karger-Kocsis J.: Self-healing properties of epoxy resins with poly( $\varepsilon$-caprolactone) healing agent. Polymer Bulletin, 73, 3081-3093 (2016).

https://doi.org/10.1007/s00289-016-1642-2

[50] Cohades A., Manfredi E., Plummer C. J. G., Michaud V.: Thermal mending in immiscible poly( $\varepsilon$-caprolactone)/ epoxy blends. European Polymer Journal, 81, 114-128 (2016).

https://doi.org/10.1016/j.eurpolymj.2016.05.026 